\title{
Challenges to Physiotherapy Practice in COVID-19 times
}

Thanks largely to Dr Li Wenliang, the world became aware of a new type of coronavirus, similar to severe acute respiratory syndrome (SARS), in early December 2019. It would eventually be named coronavirus disease 2019 or COVID-19 (World Health Organization, 2020a). As of 13 September 2020, COVID-19 had already infected approximately 28,919,000 people and was responsible for 924,619 deaths worldwide (World Health Organization, 2020b). Measures taken to restrict the spread of this virus, such as "lockdown" strategies, have created a multitude of difficulties in the healthcare system, including cessation or reduction of outpatient and home-care services, which in turn have made rehabilitation challenging. Consequently, the Chartered Society of Physiotherapy in the United Kingdom has predicted a "tsunami of rehabilitation needs", particularly for patients who have been ventilated in an intensive care unit (ICU) (Thornton, 2020). Since the focus of healthcare systems worldwide has shifted to the needs of COVID-19 patients, the medical and rehabilitation needs of non-COVID patients have also been compromised, and this situation has created inequity of healthcare access for a variety of people with disabilities and/or frailties (De Biase et al., 2020). Physiotherapy services have also been impacted. To overcome these challenges, changes are needed in healthcare delivery as well as the way we think and practice. A comprehensive policy, which addresses all issues related to COVID and non-COVID patients would be beneficial to ensure the needs of all patients are being met. Physiotherapists are also facing multiple barriers in their clinical practice, which they will continue to encounter. Some of the key factors which require consideration are as follows:

1. Protection of physiotherapists, not only to save lives but also to maintain the health of "working hands". This a primary concern, and World Physiotherapy has started an advocacy campaign to ensure the availability of personal protective equipment for all physiotherapists (World Physiotherapy, 2020).

2. Physiotherapy interventions: The experiences in Italy and China have taught the world about the importance of providing timely physiotherapy interventions (Vitacca et al., 2020; Lazzeri et al., 2020; Zhao et al., 2020). Because of the lack of randomised control trials, recommendations prescribed by various bodies should be followed, with individual modifications where required (Vitacca et al., 2020). Physiotherapy management should focus on the musculoskeletal system as well as the respiratory system, as both are affected by COVID-19. Attention should also be paid to post-ICU rehabilitation, as currently, this seems to be neglected. While rightly, the current emphasis is on saving lives, eventually the number of survivors impacted by COVID-19 will rise, necessitating an assessment of its longterm impact in terms of rehabilitation. Community-based care should be emphasised because, in upcoming months, the number of COVID-19 cases will continue to increase and care closer to home will become important.
3. Importance of physical activity: On a positive note, renewed importance has been given to exercise and physical activity, particularly to counter sedentary behaviours that have been promoted by "lockdown" (Srivastav et al., 2020). Anecdotal data suggest that there has been a surge of YouTube videos, television programmes and mobile apps related to structured exercise protocols. Instagram, Facebook and other social media platforms are also being used to spread this message. This is a healthy trend, but some deleterious effects, like an increase in the incidence of injury, have been reported, as often self-help video-based exercises are being performed without appropriate guidance. Hence prudence is advised.

4. Reorganisation of personnel and systems: Capacity building exercises need to be undertaken by physiotherapy departments. This should include short-term training courses about management strategies, and creating teams of trained professionals to deal with such a crisis. Also, staff numbers need to be increased, as ICU staff and other teams caring for patients with COVID-19 have to be separated from regular workers, although this can be managed via a structured rotation system too. Standard operating procedures have to be developed for equipment handling, and appointment systems should be adhered to in order to encourage and/or enforce social distancing norms. Orthopaedic physiotherapists need to revisit the evidence for hands-on treatment for some clinical conditions. Telerehabilitation is the need of the hour.

5. Effective communication and the sharing of information among professional members. This plays an important role in addressing common issues, hence, any barriers to the effective functioning of interdisciplinary teams must be removed.

The COVID-19 pandemic has changed the world. We too have to change and adapt. This change must be reflected from the mode of delivery to the methods of delivery. As healthcare professionals, physiotherapists have to strive to impart the best service to all patients, while keeping personal safety in mind. This may bring about much-needed change in understanding the importance of rehabilitation, which might lead to the development of standard operating procedures, an increase in finances and effective management which will benefit everyone (Wade, 2020). Healthcare professionals will not only endure, but will thrive, if they work together as an interdisciplinary team (Wade, 2020).

Zubia Veqar PhD

Associate Professor, Centre for Physiotherapy and Rehabilitation Sciences

Jamia Millia Islamia, New Delhi-110025, India

Email: veqar.zubia@gmail.com

https://doi.org/10.15619/NZJP/48.3.07 


\section{REFERENCES}

De Biase, S., Cook, L., Skelton, D. A., Witham, M., \& ten Hove, R. (2020). The COVID-19 rehabilitation pandemic. Age and Ageing, 49(5), 10-14. https:// doi.org/10.1093/ageing/afaa118

Lazzeri, M., Lanza, A., Bellini, R., Bellofiore, A., Cecchetto, S., Colombo, A., D'Abrosca, F., Del Monaco, C., Gaudiello, G., Paneroni, M., Privitera, E., Retucci, M., Rossi, V., Santambrogio, M., Sommariva, M., \& Frigerio, P. (2020). Respiratory physiotherapy in patients with COVID-19 infection in acute setting: A Position Paper of the Italian Association of Respiratory Physiotherapists (ARIR). Monaldi Archives for Chest Disease, 90(1), 163168. https://doi.org/10.4081/monaldi.2020.1285

Srivastav, A. K., Sharma, N., and Samuel, A. J. (2020). Impact of Coronavirus disease-19 (COVID-19) lockdown on physical activity and energy expenditure among physiotherapy professionals and students using webbased open E-survey sent through WhatsApp, Facebook and Instagram messengers. Clinical Epidemiology and Global Health. Advance online publication. https://doi.org/10.1016/j.cegh.2020.07.003

Thornton, J. (2020). Covid-19: The challenge of patient rehabilitation after intensive care. BMJ, 369, m1787. https://doi.org/10.1136/bmj.m1787

Vitacca, M., Carone, M., Clini, E. M., Paneroni, M., Lazzeri, M., Lanza, A., Privitera, E., Pasqua, F., Gigliotti, F., Castellana, G., Banfi, P., Guffanti, E., Santus, P. \& Ambrosino, N; on behalf of the ITS- AIPO, the ARIR and the SIP/IRS. (2020). Joint statement on the role of respiratory rehabilitation in the COVID-19 crisis: The Italian position paper. Respiration, 99(6), 493499. https://doi.org/10.1159/000508399
Wade, D. T. (2020). Rehabilitation after COVID-19: an evidence-based approach. Clinical Medicine, 20(4), 359-365. https://doi.org/10.7861/ clinmed.2020-0353

World Health Organization (2020a). Naming the coronavirus disease (COVID-19) and the virus that causes it. https://www.who.int/emergencies/ diseases/novel-coronavirus-2019/technical-guidance/naming-thecoronavirus-disease-(covid-2019)-and-the-virus-that-causes-it

World Health Organization. (2020b). WHO coronavirus disease (COVID-19) dashboard. https://covid19.who.int/

World Physiotherapy. (2020). \#PPE4PT advocacy campaign. https://world. physio/covid-19-information-hub/ppe4pt-advocacy-campaign

Zhao, H. M., Xie, Y. X., \& Wang, C. (2020). Recommendations for respiratory rehabilitation in adults with coronavirus disease 2019 Chinese Medical Journal, 133(13), 1595-1602. https://doi.org/10.1097/ CM9.0000000000000848 